\title{
A CONCEPÇÃo dE EDUCAÇÃo E ESCOLA DE WILliam KilPaTRICK E RUDOLF STEINER E SUAS CONTRIBUIÇÕES PARA A EDUCAÇÃo CONTEMPORÂNEA
}

\author{
THE EDUCATION AND SCHOOL CONCEPTION OF WILLIAM KILPATRICK AND RUDOLF \\ STEINER AND THEIR CONTRIBUTIONS TO THE CONTEMPORARY EDUCATION
}

LA CONCEPCIÓN DE EDUCACIÓN Y ESCUELA DE WILLIAM KILPATRICK Y RUDOLF STEINER Y SUS CONTRIBUCIONES PARA LA EDUCACIÓN CONTEMPORÁNEA

\section{Helena Maria Rodrigues de Paula (iD) \\ Mestranda em Educação pela Universidade Federal de Mato Grosso (PPGE/UFMT) \\ Professora no Colégio Waldorf Brasilis \\ helenamariardp@gmail.com}

\section{Evando Carlos Moreira (iD) 9}

Doutor em Educação Física pela Universidade Estadual de Campinas (UNICAMP) Professor na Universidade Federal de Mato Grosso (UFMT)

Docente do Programa de Pós-

Graduação em Educação

(PPGE/UFMT)

ecmmoreira@uol.com.br

\begin{abstract}
Resumo
Os processos de educação escolar no Brasil e no mundo têm sido questionados quanto à sua efetiva contribuição para a vida de crianças e jovens, bem como para os adultos que se tornarão. Dessa forma, o presente ensaio tem como objetivo refletir sobre os pressupostos teóricos de William Kilpatrick, na obra "Educação para uma civilização em mudança" (1978), e de Rudolf Steiner, nas obras "A prática pedagógica" (2000) e "Fundamentos da Arte de Educar" (2015), quanto à organização do ensino, ao papel do professor e à avaliação da aprendizagem, tendo como elemento central uma educação para aprender a desenvolver um pensamento livre e democrático. Pressupomos que tais concepções teóricas podem contribuir para a melhoria da educação e para a formação contemporânea a partir de experiências vivas e significativas para crianças e jovens. Sugere-se ainda que o trato pedagógico e a sua postura diante do que vem a ser o conhecimento seja transformado para que a sociedade também se transforme, todavia, para isso, o trabalho em sala de aula precisa ser vivo, criando condições para a construção do pensamento livre de ideologias e de massificação. Palavras-chave: Pedagogia de Projetos; Pedagogia Waldorf; Pensamento Livre.
\end{abstract}

Recebido em: 7 de janeiro de 2021.

Aprovado em: 2 de março de 2021.

Como citar esse artigo (ABNT):

PAULA, Helena Maria Rodrigues de; MOREIRA, Evando Carlos. A concepção de educação e escola de William Kilpatrick e Rudolf Steiner e suas contribuições para a educação contemporânea. Revista Prática Docente, v. 6, n. 1, e008, 2021. 


\begin{abstract}
The processes of school education in Brazil and in the world have been questioned in regards to its effective contribution to the life of children and youth, as well as to the adults they will become. Therefore, the present essay has as aim to reflect about the theoretical assumptions of William Kilpatrick, in the work "Education to a civilization in change" (1978), and of Rudolf Steiner, in the works "The pedagogical practice" (2000) and "Fundaments of the Art of Teaching" (2015), in relation to the organization of the teaching, to the teacher's role and to the evaluation of the learning, having as central element an education to learn to develop free and democratic thought. We assumed that such theoretical conceptions could contribute to the improvement of education and to the contemporary formation from lively and meaningful experiences to children and youth. It is still suggested that the pedagogical tract and its attitude towards what is knowledge is transformed so that society also gets transformed, however, to do so, the work in the classroom must be alive, creating conditions to the construction of free thinking from ideologies and massification.
\end{abstract}

Keywords: Project-based Pedagogy; Waldorf Pedagogy; Free Thought.

\title{
Resumen
}

Los procesos de educación escolar en Brasil y en el mundo han sido cuestionados cuanto su efectiva contribución para la vida de niños y jóvenes, así como para los adultos que serán. Por esto el presente ensayo tiene como objetivo reflejar sobre los presupuestos teóricos de William Kilpatrick, en la obra "Educación para una civilización en camino" (1978), y de Rudolf Steiner, en las obras "La practica pedagógica" (2000) y "Fundamentos del Arte de Educar" (2015), cuanto la organización de la enseñanza, el papel del profesor y la evaluación de la enseñanza, teniendo como elemento central la educación para aprender a desenrollar pensamiento libre y democrático. Suponemos que tales concepciones teóricas pueden contribuir para la mejoría de la educación y para la formación contemporánea a partir de experiencias vivas y significativas para niños y jóvenes. También se sugiere que el tracto pedagógico y su postura ante do que es conocimiento sea transformado para que la sociedad también se transforme, pero, para hacer esto, el trabajo de clase necesita ser vivo, creando condiciones para la construcción de un pensamiento libre de ideologías y de masificación.

Palabras clave: Pedagogía de Proyectos; Pedagogía Waldorf; Pensamiento Libre. 


\section{INTRODUÇÃo}

O presente ensaio tem como objetivo refletir sobre os pressupostos teóricos de William Kilpatrick, na obra "Educação para uma civilização em mudança” (1978), e de Rudolf Steiner, nas obras “A prática pedagógica" (2000) e "Fundamentos da Arte de Educar" (2015), quanto à organização do ensino, ao papel do professor e à avaliação da aprendizagem, tendo como elemento central uma educação para o desenvolvimento do pensamento livre e democrático.

Os dois teóricos apresentam em suas obras a preocupação com uma escola viva, democrática, com os conteúdos de ensino, com o papel dos professores e com um sistema de avaliação que reconheça as capacidades individuais de cada estudante, considerando o processo mais importante do que o resultado. Diferem na concepção quanto à visão de ser humano e a sua relação com a educação escolar, mas nem por isso deixam de apresentar elementos alternativos e importantes para superação de procedimentos educacionais que não se sustentam mais pela sua simples existência, pois apresentam-se desprovidos de sentidos e de significados para os alunos.

Dessa forma, apresentaremos a compreensão sobre a obra dos autores para, após as referidas contextualizações e aproximações, realizar o entrelaçamento entre ambos, de maneira a evidenciar como obras produzidas em momentos e locais tão distintos podem tornar-se fonte de uma educação contemporânea mais humana e fraterna.

\section{William KilPATrick: PROFESSORES, CURRÍCUlos E AVALIAÇÃo PARA PENSAMENTOS E AÇÕES MELHORES}

Kilpatrick (1871-1965), professor, estruturou, a partir da sua prática pedagógica, o Método de Projetos em 1918, fundamentando seu pensamento e método a partir da perspectiva de que uma sociedade em mudança apresenta novas exigências para a educação.

Segundo o autor, a educação precisava caminhar junto com os processos de mudança, tendo em vista que vivia um período pós-Primeira Guerra Mundial, com grandes impactos e transformações em todos os segmentos sociais.

Dessa forma, o termo projeto foi escolhido como o conceito que mais aproximava-se da proposta de Kilpatrick, visto o ato propositivo do aluno como a intenção a ser atingida pela ação pedagógica. Contudo, as dúvidas e as críticas ainda fazem desta proposta um campo incerto para muitos professores, como cita Pondé (2019). 
Na obra Educação para uma civilização em mudança (1978), Kilpatrick aponta a natureza desta civilização em mudança e o que ela exige da educação. É categórico ao apontar a necessidade da reformulação das teorias de educação vigentes, estagnadas, conteudistas e conservadoras para uma escola renovada que diminua o atraso moral-social em relação às inovações do progresso, cada vez globalizadas. "Em lugar de preparar, como melhor podia para um futuro desconhecido, em mudança, a educação tradicional, com efeito, pretendeu que o futuro fosse igual ao presente" (KILPATRICK, 1978, p. 86).

Para o autor, a escola deve ser permeada de um viver real e verdadeiro. Uma sociedade só viverá nos princípios democráticos se estes fizerem parte do ensino da escola. Para que este cenário democrático e ético se configure, são necessárias mudanças significativas no sistema de ensino, incluindo o protagonismo do papel do professor, a organização do ensino e a avaliação da aprendizagem.

A democracia é vista pelo autor como um bem a ser cultivado, ainda mais em tempos de intensas mudanças e num contexto histórico que ainda sofria os efeitos de guerras e de regimes autoritários. A educação precisa estar permeada por princípios democráticos para que os indivíduos cultivem a democracia enquanto uma conduta moral da vida social.

Diante da realidade social e histórica da qual falava, Kilpatrick argumentava que a educação só conseguiria acompanhar os processos de mudanças advindas do progresso, cada vez mais dinâmico, se a escola fosse renovada, reformulada tanto nas apresentações físicas quanto na organização do ensino e das posturas de quem o conduz.

Ao apontar o pensamento baseado na experimentação como o marco inicial da configuração desta civilização em mudança, o autor aponta no método de projetos a possibilidade da experimentação como construção do conhecimento e desenvolvimento das relações sociais.

Para o autor, ao dizer que o mais difícil não seria conseguir os recursos financeiros, mas encontrar professores comprometidos com este ensino para a democracia e com apreço e simpatia pela juventude, entende-se que a postura do professor é um dos eixos principais desta engrenagem (KILPATRICK, 1978).

Aos professores caberia a tarefa de estimular os estudantes para o desenvolvimento de um pensamento crítico, individual e social, mesmo que não concordassem com suas conclusões. As discussões, os questionamentos e a construção de novos pontos de vista são fundamentais para a consolidação da democracia, dentro e fora da escola. O professor deve ser um mediador, 
alguém que abre caminhos, que considera os saberes que o aluno traz consigo, que cria um ambiente de colaboração e de esforço com os alunos, propiciando que as metas estabelecidas por eles sejam alcançadas. Quando o professor se coloca nesta posição, a postura dos alunos deixa de ser arredia e até mesmo indisciplinada, assumindo mais responsabilidade e envolvimento no que realiza. Constrói-se, ao mesmo tempo, uma consciência social, com atitudes positivas, as quais, por sua vez, estimulam novas atitudes positivas. Os desacertos não são avaliados como fracassos pessoais ou erros, mas oportunidades de aprender a fazer ou de deixar de fazer algo. Aos poucos o professor deve tornar-se desnecessário para os alunos, sem perder o seu respeito.

Ao expor sua proposta para a organização das matérias curriculares, Kilpatrick rechaça o fato de como elas são utilizadas para manter a disciplina dos alunos e que a sua aplicabilidade na vida real dos alunos é quase nula, de forma que estas devem ser ensinadas quando se tornarem uma necessidade para o aluno, na execução de seus projetos e na resolução de problemas.

Não há um programa de ensino com matérias prefixadas. No lugar, existe a construção, por meio da colaboração entre professores e alunos, de um programa que deve ser funcional, repleto de sentido e de intenção para o grupo. Isto implica que o professor se prepare, tenha planos para alcançar o máximo de autonomia de cada aluno. No entanto, o plano de desenvolvimento e os conteúdos que serão trabalhados nascem das perguntas/problemas apontadas pelos alunos que, por sua vez, participam de todas as etapas do projeto, pois é uma construção coletiva.

Os projetos podem ser simples, rápidos ou complexos e com um tempo maior, mas irão abarcar diferentes conteúdos e informações pelas quais os alunos deverão se movimentar e promover a finalização da atividade, ou seja, alcançar a intenção estabelecida.

Entre os teóricos do século XX que reelaboraram as ideias de Kilpatrick, destaca-se Fernando Hernández, que estabelece os critérios para a elaboração e execução de projetos:

- Parte-se de um tema ou problema negociado com a turma.

- Inicia-se um processo de pesquisa.

- Buscam-se e selecionam-se fontes de informação.

- Estabelecem-se critérios de ordenação e de interpretação das fontes.

- Recolhem-se novas dúvidas e perguntas.

- Estabelecem-se relações com outros problemas.

- Representa-se o processo de elaboração do conhecimento que foi seguido 
- Recapitula-se (avalia-se) o que se aprendeu.

- Conecta-se com um novo tema ou problema. (HERNÁNDEZ, 1998, p. 81)

Ao professor também cabe a liberdade de agir na condução do trabalho coletivo, considerando as quatro leis da aprendizagem estabelecidas por Kilpatrick (1978) e citadas por Pondé (2019): lei da prontidão; lei do efeito; lei do exercício; e lei do conjunto ou atitude, as quais devem fazer parte do projeto em maior ou menor grau.

Ao tratar das leis de aprendizagem, Kilpatrick caracteriza o ato de aprender como a aquisição de um determinado comportamento, o qual só é conquistado por meio da prática. Contudo, esta atividade, a prática, deve estar permeada de sentido e ser bem sucedida.

Ao referir-se à liberdade de escolha e à construção dos projetos por parte dos professores e alunos, Kilpatrick (1978) afirma que o ensino precisa ser uma arte liberal e não uma ação mecânica: "o ensino precisa ser a arte mais elevada, baseada na liberdade da ciência e da filosofia. Só a esse ensino é que a sociedade pode confiar a sua própria continuidade" (KILPATRICK, 1978, p. 87).

Neste contexto, o ensino da ciência (pensar científico) deve fazer parte da aprendizagem de todos os estudantes, devendo caminhar junto com a nova escola. Contudo, o rigor do pensamento baseado na experimentação também deve ser aplicado nas ciências sociais, na construção do pensamento crítico, inclusive com relação aos grandes avanços da tecnologia e às mudanças provocadas pela industrialização, os quais impõem uma educação especializada e cada vez mais fragmentada, o que conduz à perda da identidade com o todo.

Assim, a aprendizagem precisa ser real, com sentido, com êxito, ainda que por meio de um aparente fracasso, posta em prática na vida social, constituída no tempo apropriado, consonante aos interesses do estudante e promotora da vida em democracia, conduzida pela construção do pensamento livre e da conduta moral e social.

Este conhecimento se consolida por associações através de múltiplas aprendizagens ao mesmo tempo, num espaço constituído de vontade e emoções. $\mathrm{O}$ aprendizado parte do interesse do aluno e deve ser ativo, contemplando os conhecimentos já adquiridos pela cultura e as experiências individuais, mas transformando-os, criando novas condições e significados. Embora cada aluno aprenda de forma individualizada, esse aprendizado é compartilhado com o grupo. Os conteúdos podem e devem ter um caráter globalizado, atingindo as diferentes possibilidades de aplicabilidade, bem como suas relações com a ética e com a vida social.

Kilpatrick afirma que a escola renovada com base na democracia precisa de um sistema de avaliação condizente com seus princípios. É preciso confiar, dar liberdade aos alunos e esta 
liberdade no agir é concedida de acordo com sua capacidade e maturidade. O professor terá alcançado êxito quando os alunos forem independentes dele e suas decisões e ações não forem guiadas pelo egoísmo.

A avaliação será sobre o que cada um aprendeu, individual e coletivamente. Esta acontece ao final do projeto, mas também no decorrer dele. Todavia, não é mensurada por uma nota, ainda que sejam realizados exames, pois cada criança é única, muito complexa e cheia de possibilidades. Os objetivos são estabelecidos pelos professores, enquanto as habilidades são alcançadas pelo grupo, porém cada criança recebe a confiança de que conseguirá atingi-los a partir de suas potencialidades. $\mathrm{O}$ importante é o processo em si não somente o resultado final.

Kilpatrick não se refere a uma idade adequada para que as crianças adentrem a vida escolar, mas sim que as suas capacidades e interesses sejam acolhidos e traduzam-se no planejamento, na organização, na execução e na avaliação de um projeto. Destaca ainda que é preciso que o projeto tenha um caráter social, devendo partir de perguntas manifestadas pelos alunos. Cada grupo, de acordo com a maturidade, receberá conteúdos mais ou menos complexos. No entanto, não há um critério diretamente ligado à idade, mas sim ao interesse, à necessidade da vida real, ao sentido e à finalidade para determinada situação. Por meio da participação ativa, os estudantes adquirem responsabilidade, atitudes altruístas, autonomia, criticidade e consciência individual e coletiva para viver numa sociedade democrática.

Por fim, Kilpatrick aponta ainda que, a partir de um contexto sócio-histórico que começava a sentir os efeitos da crescente globalização, as mudanças permeavam todos os âmbitos da vida social, econômica e política e à educação cabia, e ainda cabe, ser a porta de acesso, ser o elo que permite ao homem olhar para o passado, viver o presente e, na junção e na reformulação dos conhecimentos, preparar-se para o futuro e, portanto, o ensino também precisa ser globalizado.

Muitas teorias surgiram e foram implementadas, mas as causas do fracasso da educação, apontadas por Kilpatrick, ainda existem e agora juntaram-se a tantas outras. Pressupõe-se que isso ocorre porque nem todos os Estados sejam democráticos e naqueles que o são nem todos os seus cidadãos são contemplados com os direitos da democracia, ou seja, para que exista uma transformação educacional ocorra, uma transformação social também faz-se necessária. 


\section{Rudolf Steiner: o EnSino COMO CAMinho PARA O SER HUMANO APRENDER A} APRENDER

Após a Primeira Guerra Mundial, a Alemanha via-se diante de um cenário caótico. Algumas pessoas procuravam uma nova estrutura de sociedade, temendo o prelúdio de uma nova crise social, econômica e política. Rudolf Steiner (1861-1925), filósofo e professor, criador da Antroposofia e da Pedagogia Waldorf, também a partir de 1918, começa a apresentar em suas palestras um novo pensamento pedagógico.

Tendo por base Antroposofia, um método de conhecimento da natureza do ser humano e do universo, um caminho em busca da verdade para o abismo que separa historicamente a fé da ciência, Steiner criou em 1919 a Pedagogia Waldorf, atendendo ao pedido de Emil Molt.

Molt era diretor da fábrica de cigarros Waldorf-Astoria e estudioso da Antroposofia. Ele já promovia cursos e escolarização para os seus funcionários, contudo, diante da desesperança instaurada pela guerra e o temor que uma nova revolução pudesse acontecer, buscava uma escola que possibilitasse formar uma nova maneira de pensar e de perceber o mundo e as pessoas.

Em 07 de setembro de 1919, a primeira Escola Waldorf foi inaugurada em Stuttgart, Alemanha, mas era chamada por Steiner de Escola Livre. Carlgren e Klingborg (2014) citam que no discurso de inauguração Steiner frisou que, embora as bases da Pedagogia Waldorf fossem a cosmovisão Antroposófica, o objetivo da escola Waldorf não era reproduzir esta visão de mundo, mas sim garantir que as crianças e os jovens ali recebidos pudessem ser guiados na construção livre do seu próprio pensar. Já naquele momento ele alertava aos futuros professores para as consequências pedagógicas futuras caso a escola caminhasse para uma escola industrializada.

Nascia uma experiência única na Alemanha e no mundo, uma escola comunitária, gerida por pais e professores, passível de receber doações e incentivos, mas sem que para isso tivesse que submeter sua proposta pedagógica. Esta primeira escola atendia alunos de todas as classes sociais, com 8 classes, aproximadamente 300 alunos e unia na mesma sala meninos e meninas. Nos anos seguintes, foi implantado o Ensino Médio. As últimas classes a surgirem foram as do Jardim de Infância, mas sem o intuito de alfabetizar, preservando a criança até os sete anos em ambiente similar ao doméstico e entregue ao brincar livre. Por conta disso, ao ser criado o Jardim de Infância na Escola Waldorf, seu pilar foi a preservação da infância e do brincar livre sem a condução para a alfabetização. 
A garantia da liberdade da vida cultural significava a estrutura de um sistema de ensino pautado no respeito ao desenvolvimento saudável do ser humano, estimulando suas potencialidades e criatividade, sem ficar restrito a um sistema de ensino que tem como metas apenas satisfazer objetivos políticos e empresariais.

De acordo com a concepção de Steiner, o ser humano deve crescer livre das exigências do poder público e da vida econômica, até que ele próprio possa participar como concidadão ativo na configuração destes ramos da sociedade. (CARLGREN; KLINGBORG, 2014, p. 11)

A formação dos professores da primeira escola Waldorf, chamada de Escola Livre, foi realizada por Steiner num ciclo de palestras denominado Seminário de Antropologia Geral do Homem ou A Arte de Educar, distribuído em três turnos. Pela manhã eram ministradas palestras sobre Antropologia Geral, segundo a Antroposofia. Durante a tarde trabalhava-se metodologia e didática, momento em que Steiner oferecia indicações de como os conteúdos deveriam ser abordados em cada faixa etária. Por fim, durante a noite aconteciam as discussões pedagógicas com perguntas ou até mesmo com troca de experiências entre os professores.

Cabe aqui uma breve explicação sobre o que vem a ser a "antropologia geral" ou "antropologia da criança" para a Pedagogia Waldorf. Trata-se da visão do homem em seu desenvolvimento físico, psíquico e social. Além disso, como se manifesta o pensamento, o sentimento e as ações em sua relação consigo, com o outro e com o mundo. Assim, o homem é entendido com um ser físico, anímico (âmbito psíquico-emocional) e espiritual, âmbito em que se manifesta sua individualidade. O ser humano reproduz nas fases do seu desenvolvimento que Steiner dividiu em setênios - a sua biografia individual, o caminho de desenvolvimento da humanidade nos diferentes períodos de sua evolução.

A organização do ensino está pautada no desenvolvimento humano a partir dos setênios, ciclos de sete anos. Para a pedagogia Waldorf, considera-se, na organização do ensino, os três primeiros setênios ( 0 aos 7 anos, dos 7 aos 14 anos e dos 14 aos 21 anos). Depois, como adulto, o ser humano conduz sua própria educação. Steiner fundamentou seu método de ensino na fenomenologia de Goethe, um processo orgânico, que possibilita construir aos poucos a autoeducação. Esta é entendida como a autotransformação para compreensão de si e do mundo, sem dicotomizar homem e mundo, promovendo a educação crítica dos sentidos numa relação dialógica com o mundo (BACH JUNIOR, 2019) ou com o fenômeno observado, no caso os conteúdos abordados.

Partindo desta percepção da criança e das fases de desenvolvimento do ser humano, Steiner proferiu várias conferências que foram transformadas em livros, considerando três 
aspectos básicos para apresentação dos conteúdos e para organização das disciplinas escolares de acordo com a faixa etária dos estudantes:

Sentir - emoções, sentimentos, imagens - como o conteúdo chega para o aluno.

Pensar - reflexões, pensar conceitual, observação sensorial, representação mental como a criança transforma o conteúdo em algo seu.

Querer - fazer, agir, realizar as atividades, colocar sua força volitiva em ação - como a criança atua no mundo.

Frisa-se que a proporção de cada elemento é diferente em cada idade. O pensar torna-se mais conceitual de acordo com o avanço dos setênios.

Ademais, o currículo deverá ser adequado às características da comunidade, docentes e discentes, por esta razão Steiner não determinou um currículo fixo, ofereceu orientações do que a criança e o adolescente devem receber como alimento através do ensino, a cada ano. Para Steiner (2019), o ensino ou a Arte de Educar só acontece se estiver fundamentado no conhecimento do ser humano e do mundo. Contudo, vale destacar que, no ímpeto de apresentar e de vivenciar uma proposta diferenciada para os processos de organização e formação social, alguns professores das primeiras escolas Waldorf sistematizaram essas orientações pedagógicas que acabaram transformando-se num currículo Waldorf.

Este currículo, além das matérias básicas, oferece especial atenção para o ensino das artes, manualidades, movimento e educação ambiental. Entretanto, o fazer artístico não se limita às disciplinas específicas, ele deve estar presente na prática pedagógica de todos os professores. Steiner (2019) afirmava que, ao expormos a criança a uma educação apenas intelectualista, contribuímos para a degeneração de suas forças humanas. O ensino deve incorporar também os impulsos morais e espirituais, numa estrita relação entre homem e mundo. A ciência e o conhecimento não podem estar separados da arte, da visão do ser humano como uma criação artística da natureza e da religiosidade, mas devem restabelecer o vínculo entre o ser humano e a natureza que também se reflete nas relações sociais. $\mathrm{O}$ ensino da ciência tem um papel muito importante na formação do adolescente, pois é a partir das experiências e das observações de fenômenos científicos que o aluno exercita sua capacidade de julgar com imparcialidade e analisar um fato sob diferentes pontos de vista. O aluno não recebe conceitos prontos. Este chega até ele desenvolvendo suas próprias conclusões.

Os livros devem servir como fontes de pesquisa e de lazer e não como padronização limitante do conhecimento, por isso na Pedagogia Waldorf não são utilizados livros didáticos. 
Os professores criam o seu repertório de conteúdos e apresentam-nos aos alunos por meio de exposições envolventes, com atividades dinâmicas, práticas, desenvolvendo a imaginação e a criatividade individual de cada aluno, o qual colabora com as aulas, expondo suas experiências e percepções. Essa forma de organização é chamada de economia do ensino.

Diante da riqueza do currículo e da exiguidade do tempo disponível, um segredo da
Pedagogia Waldorf consiste na economia do ensino, com o qual o professor deve
trabalhar. Já que a finalidade é formar os alunos, fazendo com que estes sintam o
essencial de uma disciplina, o professor pode renunciar a todos os detalhes sem nexo,
que serão logo esquecidos e só oneram a memória. Em cada matéria existem fatos,
conhecimentos, leis e relações essenciais: é isto que o aluno deve conhecer; melhor
do que conhecer uma fórmula é saber deduzi-la. Pensar matematicamente ou
historicamente vale mais do que o acúmulo de fórmulas, nomes e datas. (LANZ, 2005,
p. 102)

A alternância estabelece ritmos, respirar e expirar, durante a aula, entre as aulas, entre o dia e a noite e entre uma época e outra. Por sua vez, a avaliação na Pedagogia Waldorf não se baseia em provas. Ela consiste em uma avaliação qualitativa de como o aluno se comportou e interagiu com os conteúdos, com os colegas e com o professor, considerando a individualidade de cada aluno. Esta avaliação não aponta pontos negativos, mas o que a criança já conquistou e o que precisa conquistar. É contínua, pois a partir dela o professor também se autoavalia, partindo do princípio de que toda educação é autoeducação. Ao final do ano as famílias recebem um boletim que contém não somente os progressos intelectuais e sociais da criança ao longo do ano, mas também "uma força em si que atua até que a criança receba um novo boletim" (STEINER, 2015, p. 131). Não existe o princípio da repetência numa escola Waldorf. O aluno sempre segue com sua turma e, se porventura existem dificuldades na aprendizagem, recebe apoio pedagógico para superá-las.

Segundo a Federação das Escolas Waldorf do Brasil (FEWB, 2020), o objetivo da Pedagogia Waldorf “é a formação de pessoas livres, sensíveis e criativas é feita com base nos valores da fraternidade e responsabilidade, consciência de grupo, alimentação saudável e a relação respeitosa e produtiva com a natureza". Steiner (2000), ao falar dos objetivos sociais da educação, afirma que para atingirmos estes objetivos precisamos considerar o cultivo de três virtudes fundamentais: tudo o que vive na vontade ligado à gratidão; tudo o que vive na vontade ligado ao amor; tudo o que vive na vontade ligado ao dever.

Estas virtudes converter-se-ão com a chegada da maturidade em uma postura éticomoral diante vida, do outro e do mundo. 
Para que isto concretize-se, o professor deve observar as três regras de ouro da arte de educar: "receber a criança com veneração; educá-la no amor; emancipá-la em liberdade" (STEINER, 2015, p. 60).

Cada turma de alunos é conduzida por um professor de classe que os acompanham do $1^{\circ}$ ao $8^{\circ}$ (em algumas escolas pode haver troca no $5^{\circ}$ ano). Ao acompanhar seus alunos por um longo período, o professor constrói uma relação de confiança, de autoridade amada e de profundo conhecimento das qualidades, das dificuldades e das personalidades de seus alunos. Por conhecer as necessidades do grupo e das individualidades, pode escolher a melhor forma de aplicar os conteúdos, sem deixar de prezar pelo cultivo do artístico e de todos os aspectos que corroboram para desenvolver o intelecto, as emoções saudáveis e a firme vontade no agir.

Até o $8^{\circ}$ ano o professor é um generalista, ensina de forma globalizada todo conteúdo. A partir do $9^{\circ}$ ano sai a figura do professor de classe e assume o tutor e os professores passam a ser especialistas. Contudo, organização das aulas e atividades práticas continuam cada vez mais intensas, pois os jovens precisam desenvolver ações para a vida social.

Ao professor não cabe tornar o aluno uma cópia de si mesmo, pelo contrário, seus alunos devem superá-lo. Para Steiner (2015, p. 12), "na escola não devemos aprender para saber, mas aprender para que, na vida, sempre possamos aprender".

A Pedagogia Waldorf busca a formação integral do homem, promovendo ao longo destes anos escolares o "desenvolver" destas qualidades morais/emocionais e das habilidades físico/motoras para que o jovem consiga expressar-se em liberdade, sem com isto ferir o direito de liberdade do outro, tão pouco descuidar-se da sua responsabilidade pelo meio em que está inserido.

\section{EnTRELAÇANDO CONCEPÇões E AÇÕES DE KILPATRICK E STEINER}

Kilpatrick e Steiner, descontentes com a realidade dos sistemas de ensino com os quais se deparavam, elaboram suas próprias concepções filosóficas de Educação, sem deixar de considerar em suas teorias outros filósofos e cientistas eminentes. Consideram importantes para o ensino a arte e a ciência, bem como a liberdade para a escolha e para a organização dos conteúdos.

O objetivo de ambos confluí para a liberdade individual e moral da vida em sociedade. Tanto a Pedagogia de Projetos quanto a Pedagogia Waldorf entendem que a educação precisa ser viva, prática e, para isto, o papel do professor é primordial. 
Em ambas concepções, o professor deixa de ser a figura autoritária, transmissor de um conhecimento pronto para ser uma figura respeitada, incentivadora e que permite aos alunos expressarem-se na sua individualidade, assumindo um papel de organizador, de condutor e de mediador das ações que os alunos realizarão, isto é, torna-se coadjuvante para que o aluno seja protagonista de sua própria história.

Professores que atuam neste formato de ensino não apresentam conceitos prontos em suas aulas. Os alunos descobrem, constroem, criam e recriam e depois concluem.

Na Pedagogia de Projetos, por exemplo, a partir de uma situação problema como "reciclagem", o professor elabora junto com os alunos um plano de trabalho e seu objetivo. A execução pode ser em grupo ou individual, mas demanda pesquisa de conteúdos de diferentes componentes curriculares, o que permite ao aluno conhecer as diferentes vertentes ligadas ao tema. O professor é o mediador, mas também aprende junto, questiona e incentiva. Os alunos apresentam percepções diferentes ao mesmo tempo que atuam, refletem e avaliam a própria prática, assim como os aspectos éticos ligados ao tema. Assim, a partir da sua pesquisa, do seu interesse, da sua prática e da sua reflexão, o aluno constrói o seu conhecimento vivo. Aprende a fazer fazendo.

O mesmo assunto abordado na Pedagogia Waldorf também não chegará por meio de conceitos prontos. Permeará a construção dos hábitos diários. Entende-se que antes do pensar é preciso atuar no sentir. Poderá ser trabalhado com os alunos das séries iniciais através do plantio de uma horta, onde os pequenos realizam todas as etapas desde a preparação da terra até a colheita, a reciclagem e a compostagem que vira adubo. Entremeado com esse trabalho na terra, cultiva-se o respeito e a veneração pela natureza e o trabalho a partir de imagens que o professor elabora com histórias e exemplos que enriquecem a fantasia e a criatividade. As crianças aprendem as tecnologias primordiais para mais tarde dominarem as digitais atuais. Textos, cálculos e atividades artísticas ligados ao tema são produzidos com as crianças, nunca perdendo de vista o vínculo do ser humano com o mundo. Numa turma de alunos maiores, o mesmo tema pode ser abordado nas aulas de química com experiências de fermentação e de decomposição. Nada é decorado, mas vivenciado com sentimento, com a força da vontade expressa no pensar e no agir, num constante ir e vir do todo para as partes e das partes para o todo. Nada é pronto e acabado, aprende-se a pensar sobre o conteúdo cognitivamente e subjetivamente, expandindo-se do concreto para o abstrato, sem o significado das relações. 
Embora Rudolf Steiner agregue uma concepção mais ampla do ser humano, considerando além dos aspectos biológicos, os aspectos anímicos, sua proposta de educação enxerga cada aluno como uma individualidade que traz consigo várias experiências e isso precisa ser valorizado pelo professor. A valorização das individualidades e a postura do professor são também contempladas na proposta de Kilpatrick. Por esta razão, os dois teóricos não consideram a avaliação quantitativa eficaz na formação dos alunos e defendem a confiança na criança, validando suas qualidades morais e as infinitas possibilidades que cada um pode desenvolver.

\section{CONSIDERAÇÕES FINAIS}

A partir da leitura, análise e reflexão das obras de Kilpatrick e Steiner, percebe-se um movimento para que a educação, por meio da escola, ofereça à humanidade possibilidades de desenvolvimento de um pensar livre e que esta liberdade se expresse através de uma sociedade democrática, não apenas no regime político como também na conduta moral de cada indivíduo.

Os autores, expectadores de momentos de intensas mudanças tecnológicas e de desigualdades sociais, não desprezam a ciência, mas alertam para os desequilíbrios da crescente industrialização e apontam caminhos, ainda que diferentes, de como o pensar científico pode contribuir para a conduta ética e social.

As duas propostas pedagógicas ainda são consideradas por muitos como inseguras seja por permitirem seus alunos expressarem-se com liberdade e responsabilidade, seja por não acreditarem na eficácia das provas escolares que ainda são instrumentos de poder, de controle e de estigma para com os estudantes.

É evidente que as dificuldades apontadas por Kilpatrick e Steiner quanto ao grande progresso tecnológico e ao atraso da educação, bem como o descuido com a formação moral das crianças e dos jovens não deixaram de existir e ganharam proporções ainda maiores. À educação ficou relegada a tarefa de apenas preparar para o mundo do trabalho, tornar o homem capaz de competir, produzir e atingir metas. Como resultado temos serem humanos doentes física, psíquica e socialmente.

Entretanto, a Pedagogia Waldorf e a Pedagogia de Projetos continuam sendo ótimas opções para as comunidades escolares - aqui vale ressaltar que estas propostas pedagógicas só obtêm êxito quando fazem parte das escolhas da comunidade (pais e professores) - que buscam não apenas instruir, informar, mas construir uma base moral, utilizando os conteúdos escolares 
como caminhos para que os estudantes descubram e desenvolvam suas potencialidades individuais e coletivas, considerando a educação não apenas o caminho para o desenvolvimento cognitivo, mas como promotora de saúde física e emocional.

Outro aspecto fundamental apontado por ambas é considerar o ser humano, as suas relações sociais e a sua relação com o meio ambiente como uma parte de um grande todo que se transforma mutuamente. Isto torna-se mais humano a partir de um ensino que valorize a ciência e a cultura, as artes, a filosofia, o pensar concreto e o pensar abstrato, a construção de conhecimento por meio da prática, da experiência, da vivência, do sentimento e da autoeducação.

Frente o exposto e considerando o cenário pandêmico que vivenciamos em escala mundial, temos percebido em poucos dias a fragilidade dos nossos sistemas de educação, seja pelas dificuldades estruturais, seja por pouco considerarem os fatores psíquicos-emocionais, biológicos e culturais dos estudantes e mesmo dos professores. Para muitos sistemas de ensino, o conhecimento se resumiu ao domínio de técnicas sem sentido e os alunos não são mais do que números. Mais uma vez nos deparamos com a velha pergunta: o que e como as crianças deveriam estar aprendendo agora?

O que as novas mudanças da civilização apontam como exigências para a educação? Pressupomos que tanto Kilpatrick quanto Steiner já tenham nos sugerido a resposta: uma educação viva, centrada no conhecimento do ser humano, conhecimento do mundo, educar para a liberdade ética.

Nossos sistemas de ensino não são livres, por isso não podem educar para a liberdade.

\section{REFERÊNCIAS}

BACH JÚNIOR, Jonas. Fenomenologia de Goethe e educação: a filosofia de educação de Steiner. Curitiba, PR: Lohengrin, 2019.

CARLGREN, Franz; KLINGBORG, Arne. Educação para a liberdade: a pedagogia de Rudolf Steiner. 14. ed. São Paulo: Escola Waldorf Rudolf Steiner, 2014.

FEDERAÇÃO DAS ESCOLAS WALDORF DO BRASIL. Fundamentos da Pedagogia

Waldorf. Disponível em: http://www.fewb.org.br/acesso. Acesso em: 05 jul. 2020.

HERNÁNDEZ, Fernando. Transgressão e mudança na educação - os projetos de trabalho. Porto Alegre, ArtMed, 1998.

KILPATRICK, William H. Educação para uma civilização em mudança. 11. ed. São Paulo: Melhoramentos, 1978. 
LANZ, Rudolf. A pedagogia Waldorf: caminho para um ensino mais humano. São Paulo: Antroposófica, 1998.

PONDÉ, Gislaine Lisboa. A metodologia de projetos do Programa a União Faz a Vida na educação física: possibilidades de uma prática pedagógica. 2019. 219f. Dissertação (Mestrado em Educação). Universidade Federal de Mato Grosso, Cuiabá, MT, 2019.

STEINER, Rudolf. A prática pedagógica. São Paulo: Antroposófica, 2000.

STEINER, Rudolf. Fundamentos da arte de educar. São Paulo: FEWB, 2015.

STEINER, Rudolf. O desenvolvimento saudável do ser humano. São Paulo: Antroposófica, 2019. 